\title{
A novel NF1 frame-shift mutation (c.702_703delGT) in a Chinese family with neurofibromatosis type 1
}

\author{
S.P. Cai ${ }^{1 *}$, N. Fan $^{1 *}$, J. Chen ${ }^{2 *}$, Z.L. Xia ${ }^{2}$, Y. Wang1, X.M. Zhou ${ }^{2}$, Y. Yin ${ }^{2}$, \\ T.L. Wen ${ }^{1}$, Q.J. Xia ${ }^{2}$, X.Y. Liu ${ }^{1}$ and H.Y. Wang ${ }^{3}$ \\ ${ }^{1}$ Shenzhen Key Laboratory of Ophthalmology, Shenzhen Eye Hospital, \\ Jinan University, Shenzhen, China \\ ${ }^{2}$ Department of Ophthalmology, West China Hospital, Sichuan University, \\ Chengdu, China \\ ${ }^{3}$ Beijing Ophthalmology \& Visual Sciences Key Lab, Beijing Tongren Eye Center, \\ Beijing Tongren Hospital, Capital Medical University, Beijing, China \\ *These authors contributed equally to this study. \\ Corresponding authors: X.Y. Liu / H.Y. Wang \\ E-mail: xliu1213@126.com / hy853@hotmail.com
}

Genet. Mol. Res. 13 (3): 5395-5404 (2014)

Received June 3, 2013

Accepted December 16, 2013

Published July 24, 2014

DOI http://dx.doi.org/10.4238/2014.July.24.19

\begin{abstract}
This study aimed to characterize the clinical features of a Chinese pedigree with neurofibromatosis type 1 (NF1) and to identify mutations in the $N F 1$ gene. In this three-generation family containing 8 members, 5 had been diagnosed with NF1 and the others were asymptomatic. All members of the family underwent complete medical examinations. Molecular genetic analyses were performed on all subjects included in the study. All exons of $N F 1$ were amplified by polymerase chain reaction, sequenced, and compared with a reference database. Possible changes in function of the protein induced by amino acid variants were predicted by bioinformatic analysis. In this family, the 5 patients presented different clinical phenotypes, but all manifested typical café-au-lait macules. One novel frame-shift
\end{abstract}


mutation, c.702_703delGT, in exon 7 of $N F 1$ was identified in all affected family members, but not in the unaffected family members or in 102 normal controls. This mutation generates a premature stop codon at amino acid position 720 . Additionally, a synonymous mutation c.702 G>A was found in 3 family members, including 2 affected and 1 normal individuals. In conclusion, our study suggests that a novel c.702_703delGT frame-shift mutation in NF1 is likely to be responsible for the pathogenesis of NF1 in this family. To the best of our knowledge, it is the first time that a c.702_703delGT mutation has been identified in a family with neurofibromatosis type 1 .

Key words: Neurofibromatosis type 1; NF1 gene; Mutation

\section{INTRODUCTION}

Neurofibromatosis type 1 (NF1; OMIM\#162200), also known as von Recklinghausen disease, is one of the most common autosomal dominant disorders in humans (Huson et al., 1989). It occurs in about 1:3500 individuals (Riccardi, 1992; Rasmussen and Friedman, 2000). Neurofibromas, which arise from peripheral nerve sheaths, are the key characteristics of NF1 (Von Deimling et al., 2000), and café-au-lait macules, axillary freckling, and Lisch nodules of the iris are also common (Huson and Hughes, 1994; Gutmann et al., 1997; Szudek et al., 2000). Café-au-lait macules and neurofibromas are frequently present from birth and increase in number with age. Skinfold freckling often appears next. Lisch nodules usually only occur in adults. The NF1 gene was first associated with NF1 in 1990 and is located on chromosome 17q11.2, spanning $350 \mathrm{kbp}$ of genomic DNA and containing 60 exons that encode the 2818 amino acid protein neurofibromin (Cawthon et al., 1990; Viskochil et al., 1990; Wallace et al., 1990). The NF1 mutation rate is among the highest observed in human genes, with estimates ranging from 1/7800 to 1/23,000 gametes (Huson et al., 1989; Clementi et al., 1990; Littler and Morton, 1990; Riccardi, 1992; Takano et al., 1992; Li et al., 1995). To date, more than 800 independent mutations in the $N F 1$ gene among different ethnic groups have been described to be associated with neurofibromatosis type 1 (Heim et al., 1995; Origone et al., 2002; Cai et al., 2005; Bausch et al., 2007; Upadhyaya et al., 1997, 2008; Bottillo et al., 2009; Messiaen et al., 2011). About half of NF1 individuals have a positive family history (Clementi et al., 1990; Takano et al., 1992; North, 1993). In this study, alterations in the NF1 gene were analyzed in a three-generation family containing 8 members, and a novel frame-shift mutation was found.

\section{MATERIAL AND METHODS}

\section{Family recruitment and clinical examination}

A three-generation pedigree with NF1 (Figure 1) was recruited from Chengdu, Sichuan Province in China. No consanguineous marriages were noticed in the family. All members of this family enrolled in the study underwent complete neurological and ophthalmologic examinations, including magnetic resonance imaging (MRI) of the central nervous system (3.0T; SIEMENS, Berlin, Germany) and slit-lamp microscopy. 


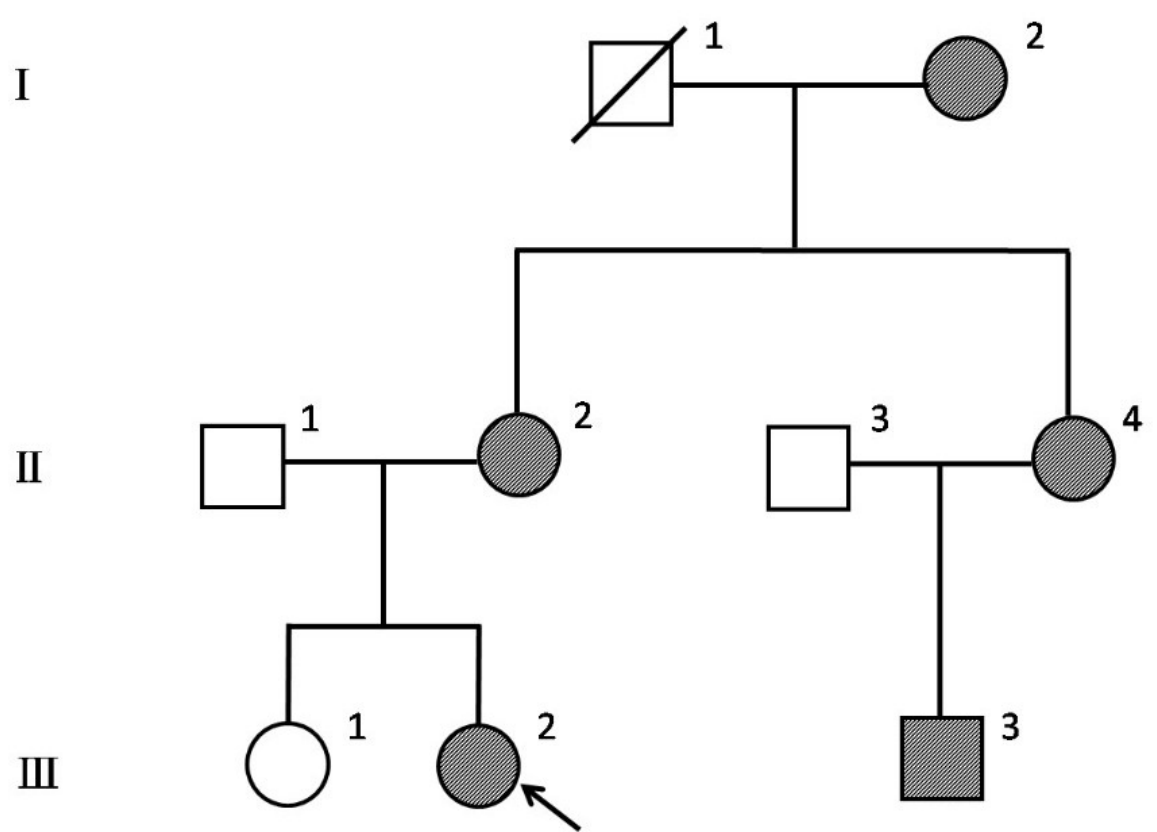

Figure 1. Pedigree of the Chinese family with neurofibromatosis type 1. Filled squares and circles are affected males and females, respectively. Arrowhead indicates proband (III-2.).

The study was prospectively reviewed and approved by the Medical Ethics Committees of both West China Hospital of Sichuan University and Shenzhen Eye Hospital of Jinan University. Written informed consent was obtained in accordance with the Declaration of Helsinki before blood samples were taken for analysis (see attachment for details). Three minors were enrolled in this study for whom written informed consent was obtained from a guardians on their behalf (see attachment for details). Neurofibromatosis type 1 was diagnosed according to criteria created by the National Institute of Health (NIH) (Anonymous, 1988; Gutmann et al., 1997; Huson and Hughes, 1994). Two or more of the following criteria are required for positive diagnosis: 1) 6 or more café-au-lait macules $>5 \mathrm{~mm}$ in maximal diameter in prepubescent individuals or $>15 \mathrm{~mm}$ in maximal diameter after puberty; 2) $2+$ neurofibromas of any type or 1 plexiform neurofibroma; 3 ) freckling in the axillary or inguinal regions; 4) an optic pathway tumor; 5) 2+ Lisch nodules (iris hamartomas); 6) a distinctive osseous lesion, such as sphenoid wing dysplasia or thinning of the cortex of long bones (with or without pseudarthrosis); or 7) a first-degree relative (parent, sibling, or child) with NF1 diagnosed by the above criteria.

\section{Mutation screening and sequence analysis of the NF1 gene}

Informed consent was obtained from all family members before peripheral blood samples were collected (see above). Genomic DNA was extracted from 0.2-mL blood samples with a Qiamp Blood Kit (Qiagen, Hilden, Germany) following manufacturer instructions. DNA integrity was evaluated using $1 \%$ agarose gel electrophoresis. All exons of $N F 1$ 
were amplified from genomic DNA of each participant by polymerase chain reaction (PCR) using the forward and reverse primers (Table 1). PCR was performed using $30-\mu \mathrm{L}$ reaction mixtures, each containing $1 \mu \mathrm{g}$ genomic DNA, 1 X PCR buffer, $1.5 \mathrm{mM} \mathrm{MgCl}_{2}, 0.3 \mathrm{mM}$ per dNTP component, $0.05 \mathrm{U}$ Taq DNA polymerase, $0.3 \mu \mathrm{M}$ forward primer, and $0.3 \mu \mathrm{M}$ reverse primer. Cycling conditions included an initial denaturation step at $94^{\circ} \mathrm{C}$ for $2 \mathrm{~min}$, followed by 35 cycles of denaturation at $94^{\circ} \mathrm{C}$ for $20 \mathrm{~s}$, annealing at $48^{\circ}-54^{\circ} \mathrm{C}$ for $30 \mathrm{~s}$, and extension at $72^{\circ} \mathrm{C}$ for $2 \mathrm{~min}$, followed by a final extension step at $72^{\circ} \mathrm{C}$ for $5 \mathrm{~min}$. The amplified products were purified using a cycle-pure kit (OMEGA; Bio-Tek, Doraville, GA, USA) and sequenced on an ABI 3730XL automated DNA sequencer (Applied Biosystems, Foster City, CA, USA). Nucleotide sequences were compared pairwise with the published NF1 sequences. Mutations were named according to the nomenclature recommended by the Human Genomic Variation Society (HGVS, http://www.hgvs.org/).

\section{Bioinformatic analysis}

The ClustalW tool (http://clustalw.ddbj.nig.ac.jp/top-e.html) was used to align neurofibromin protein sequences among 8 different species.

\section{RESULTS}

\section{Clinical findings of the pedigree}

The proband (III-2) presented neurofibromas of the right orbit and abdomen, dozens of café-au-lait macules and axillary freckling, and was diagnosed with NF1 at the age of 3 years (Figure 2). Orbital CT revealed a subcutaneous soft tissue mass of the right eyelid and sphenoid wing dysplasia. Even though MRI demonstrated many high-T2-signal-intensity brain lesions, the patient did not have dyskinesia or sensory disturbance. This patient underwent surgical excision of orbital neurofibroma, and biopsy demonstrated plexiform neurofibroma. The proband's grandmother (I-2) was diagnosed with NF1 at the age of 35 years. During examination, nearly 100 subcutaneous neurofibromas were found scattered over her whole body, with a diameter that varied widely from 2 to $6 \mathrm{~cm}$. This patient also presented sphenoid wing dysplasia and scattered café-au-lait macules. The mother of the proband (II-2) had hundreds of café-au-lait macules, iris hamartomas, and freckling in the axillary and inguinal regions. Patient II-4's clinic manifestation was similar to her mother's (I-2), but the size of subcutaneous neurofibromas was much smaller. III-3 was an 8-year-old boy, on whom only dozens of café-au-lait macules were found on his trunk and four limbs. No abnormalities were found in the rest of the family numbers.

\section{NF1 mutation identification and analysis}

Sequence analysis of NF1 revealed a novel frame-shift mutation, c.702_703delGT, in exon 7 of all 5 patients but not in any of the asymptomatic members of this family or the 102 normal controls. The c.702_703delGT mutation cosegregated with disease within this family (Figure 3). One synonymous mutation, c. $702 \mathrm{G}>\mathrm{A}$, in exon 7 of $N F 1$ was also identified in 3 family members, including 2 affected family members (I-2, III-2) and 1 normal individual (III-1) (data not shown). 
Table 1. Primers used in polymerase chain reaction for amplification of NF1.

\begin{tabular}{|c|c|c|c|}
\hline Exon & Primer direction & Primer sequence $\left(5^{\prime} \rightarrow 3^{\prime}\right)$ & Product size (bp) \\
\hline \multirow[t]{2}{*}{1} & Forward & CAGGCCGCCTTCCCTCT & 560 \\
\hline & Reverse & СТССССТСАССТАСТСТGT & \\
\hline \multirow[t]{2}{*}{2} & Forward & GTGGTTGATGCAGTTTTCCT & 351 \\
\hline & Reverse & AATCACTTTCCATACTTGAA & \\
\hline \multirow[t]{2}{*}{3} & Forward & GTAAAATGGAAGACTATTGT & 294 \\
\hline & Reverse & CATAGGACTGTCCTCTTGGT & \\
\hline \multirow[t]{2}{*}{4} & Forward & CTATCTATAGACAGATGTAG & 404 \\
\hline & Reverse & ATTACTTCAGTAGTCCCAT & \\
\hline \multirow[t]{2}{*}{5} & Forward & CCAGGCTGGTCTTGAACT & 349 \\
\hline & Reverse & CAGTTGGTGTTCTAGTTCAG & \\
\hline \multirow[t]{2}{*}{$6-7$} & Forward & CCTTTCATTGCTTACAGAT & 547 \\
\hline & Reverse & TATGTCACAAGTAGGCATT & \\
\hline \multirow[t]{2}{*}{8} & Forward & CCTTGGGTTTTTACATAGT & 638 \\
\hline & Reverse & CAGTAGCACTATATGGACAC & \\
\hline \multirow[t]{2}{*}{$9-11$} & Forward & GCTACATCTGGAATAGAAG & 1217 \\
\hline & Reverse & GAAAACCAAGAGTGCATTTCT & \\
\hline \multirow[t]{2}{*}{12} & Forward & GAAAGTTCCCGACAAAAGGAT & 350 \\
\hline & Reverse & GAAGGACCCATTCAATTCTCT & \\
\hline \multirow[t]{2}{*}{13} & Forward & GTTGGATAGCTATTATCCT & 260 \\
\hline & Reverse & GCGTTTCAGCTAAACCCAAT & \\
\hline \multirow[t]{2}{*}{14} & Forward & CCTTTAGCAGTCACTGTCT & 543 \\
\hline & Reverse & CCAAATTGAGGGTATGTGAAT & \\
\hline \multirow[t]{2}{*}{15} & Forward & CTCCAGTGTTATGTTTACCA & 1056 \\
\hline & Reverse & CGTGGCTATTGAGCACTT & \\
\hline \multirow[t]{2}{*}{16} & Forward & CTAAGCTTCTCTAAACTTGT & 292 \\
\hline & Reverse & СТСАССАТТАССАТТССАА & \\
\hline \multirow[t]{2}{*}{17} & Forward & CTCAAACAGGAAGACAACT & 297 \\
\hline & Reverse & CAGAAAACAAACAGAGCACAT & \\
\hline 18 & Forward & CTCTTGTGAGTTATTGTATG & 475 \\
\hline & Reverse & GTAGTGACCTTAAATACATT & \\
\hline $19-20$ & Forward & СТCTGCTCTTCСТАСТССТT & 575 \\
\hline & Reverse & CTGAGCGACTCTTGAAAGAT & \\
\hline $21-22$ & Forward & GTCATGGAAGAAATGTTGGAT & 1067 \\
\hline & Reverse & CTGCTACATTTCAGTAGAATG & \\
\hline $23-24$ & Forward & CCAGAAGTTGTGTACGTTCT & 847 \\
\hline & Reverse & CCACTAATACTTGAAGGTCAT & \\
\hline 25 & Forward & AGGTAGTTCCTAAGGTTTAT & 500 \\
\hline & Reverse & CCTGGTAAATGTGACTCTT & \\
\hline $26-27$ & Forward & CATTCACACCATGCACAT & 533 \\
\hline & Reverse & CCGCTTACTCTAATCACTT & \\
\hline $28-29$ & Forward & CAAGTGGTTGTCAACTTTG & 599 \\
\hline & Reverse & CTTGCTTCATGCAGTGTTAGT & \\
\hline 30 & Forward & CCCTGTCAAAGTTGTCTTT & 328 \\
\hline & Reverse & GGTAATCTCTAACTGTAAG & \\
\hline 31 & Forward & GATAACCTTCTTCTCCCAAAT & 743 \\
\hline & Reverse & CAGCTAATAAAAAGTTCTCCA & \\
\hline $32-33$ & Forward & CTCAATTCTCAACTCCTTGT & 887 \\
\hline & Reverse & CAGGTACATGGATTTATGTG & \\
\hline 34 & Forward & GTCTAATGTCAAGTCACATTG & 324 \\
\hline & Reverse & GTTCACTATCCCCATGACT & \\
\hline 35 & Forward & CATGGTCCTGAGGTCTTT & 347 \\
\hline & Reverse & GTGGCAAACTCTCCTTCT & \\
\hline 36 & Forward & TTGGTGCATGTTGCCAAAT & 297 \\
\hline & Reverse & CTGTTAAGAGACCCAAAACAT & \\
\hline 37 & Forward & ATTGATTAGTGGCATCTGT & 616 \\
\hline & Reverse & GTGACATTTTATACACCACT & \\
\hline 38 & Forward & GGCATAGTGTTTTGTTTGGT & 485 \\
\hline & Reverse & CAAACCCCAAATCAAACTG & \\
\hline 39 & Forward & TCTGTCATAGGAGCCTCA & 551 \\
\hline & Reverse & GTAAGTGAAAGTCTTCACTGG & \\
\hline 40 & Forward & GCTTTCCTTTTACCAAACTT & 587 \\
\hline & Reverse & CAATGTGGCACCAGATAAAT & \\
\hline $41-42$ & Forward & GATTAGGCTGTTCCAATGAAT & 768 \\
\hline & Reverse & GGTGTTAGAGCACAAACAT & \\
\hline $43-45$ & Forward & CAAAATGAAACATGGAACT & 901 \\
\hline & Reverse & CTTTACAACTTGAGAACCAT & \\
\hline
\end{tabular}


Table 1. Continued.

\begin{tabular}{|c|c|c|c|}
\hline Exon & Primer direction & Primer sequence $\left(5^{\prime} \rightarrow 3^{\prime}\right)$ & Product size (bp) \\
\hline \multirow[t]{2}{*}{46} & Forward & CAGCTATTACTGTATGATCA & 911 \\
\hline & Reverse & CCCAAAATGAATGCACTCAT & \\
\hline \multirow[t]{2}{*}{47} & Forward & GGAAGATAAGCTGCTTTAT & 264 \\
\hline & Reverse & TAGGAACCTCAAGGCAAAGT & \\
\hline \multirow[t]{2}{*}{48} & Forward & GGATTACTTATCTTGTCAT & 290 \\
\hline & Reverse & CAAATTACTTCTGGTTTCT & \\
\hline \multirow[t]{2}{*}{49} & Forward & СCTTTCCTTGCAGAGTTGT & 302 \\
\hline & Reverse & GTACTTTTTGGGTGATCCTT & \\
\hline \multirow[t]{2}{*}{50} & Forward & AACAGGTACTATGCTCTTT & 312 \\
\hline & Reverse & CTGCTTGCCTCCATTAGTT & \\
\hline \multirow[t]{2}{*}{51} & Forward & GTTTGTATCCTAAAGCCCTT & 424 \\
\hline & Reverse & CTTTGCTACACTGACATGGA & \\
\hline \multirow[t]{2}{*}{$52-54$} & Forward & CACTTTATGTCCAAACATT & 1043 \\
\hline & Reverse & GACAGGCACGAAGGTGAAT & \\
\hline \multirow[t]{2}{*}{$55-56$} & Forward & CACATTATTCTGGGGAAT & 676 \\
\hline & Reverse & ACCTTCATTTTGCCAAAAGT & \\
\hline \multirow[t]{2}{*}{57} & Forward & GTTGTAAGTCCTATGGTAGT & 664 \\
\hline & Reverse & AAGTTCCTCTTCCTGCCCAA & \\
\hline \multirow{2}{*}{58} & Forward & CAGACAAAATCGCCTAATGAT & 683 \\
\hline & Reverse & GGACTAACACTTTACTCTGT & \\
\hline
\end{tabular}
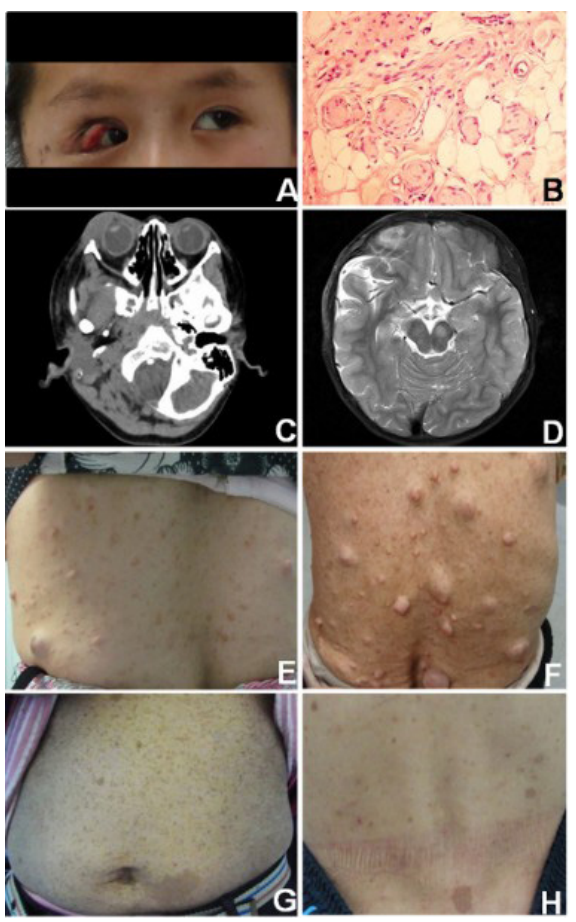

Figure 2. Clinical manifestations of patients in the Chinese family. A. Right orbital neurofibroma of proband. B. Biopsy of proband's right orbital neurofibroma. HE staining reveals that the main entity of neurofibroma is composed of spindle and oval Schwann cells; scattered Wagner-Meissner-like bodies, fibroblasts and mast cells are also noticed. C. Orbital axial CT of the proband shows sphenoid wing dysplasia on the right side and subcutaneous neurofibroma of right eyelid. D. Head axial MRI shows many high signal intensity lesions in T2-weight imaging (frontal lobe, temporal lobe and medulla oblongata). E. and F. Lots of subcutaneous neurofibromas and multiple café-au-lait macules scattered in patients II-4 and I-2, respectively. Patient II-2 (G) and patient III-3 (H) manifest café-au-lait macules in different size on their trunks. 

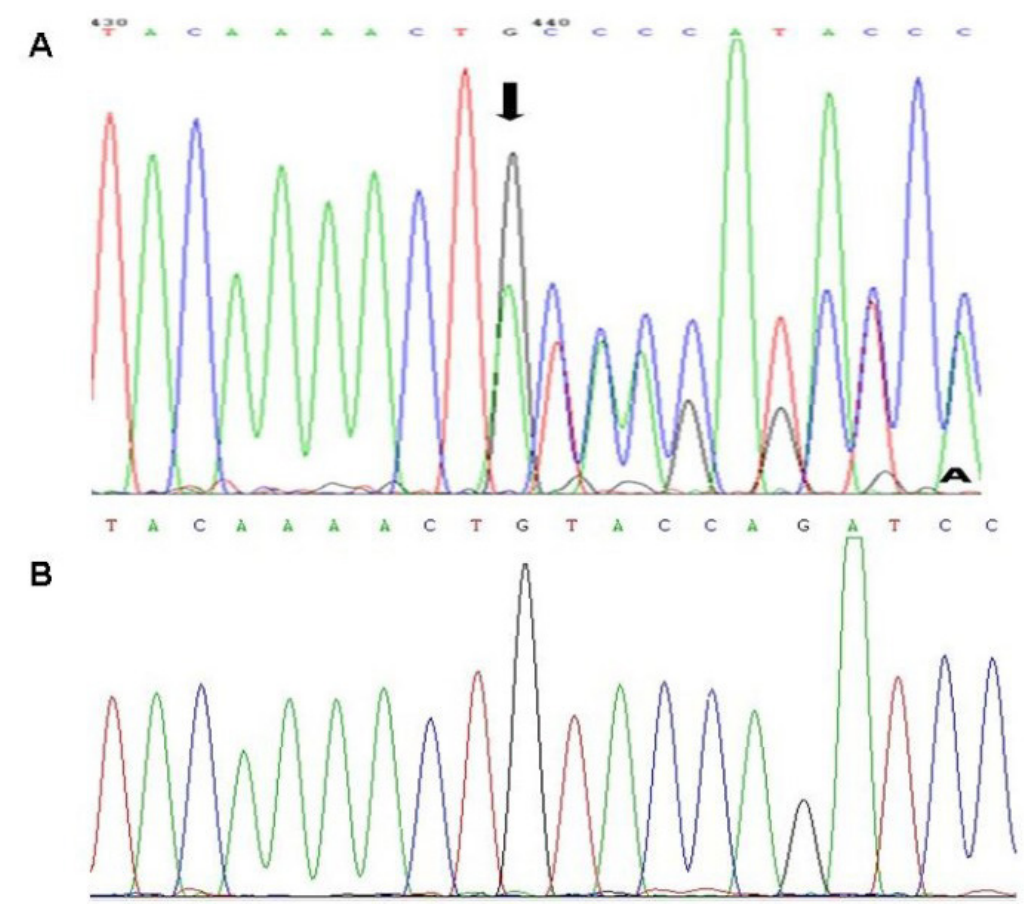

Figure 3. Sequencing results of the NF1 gene. A. Frame-shift mutation c.702_703delGT, in exon 7 of the NF1 gene (arrow) found in all patients. B. Wild-type sequence from an unaffected member.

\section{Bioinformatic analysis}

The deletion of a guanine and thymine in codon 702-703 of NF1 exon 7 caused frame shift and introduced a premature stop signal at codon 720 , which resulted in the termination of the amino acid sequence starting at position 234 of neurofibromin. The amino acid sequence around leucine in 234 was highly conserved for NF1, based on an analysis of orthologs from 8 different species by using an internet ClustalW tool (Figure 4).

$\begin{array}{ll}\text { Homo sapiens } & \text { AVINSLEKAFWNWVENYPDEFTKLYQIPQTDMAECAEKLFDLVDGFAESTKRKAAVWPLQII } \\ \text { Pan paniscus } & \text { AVINSLEKAFWNWVENYPDEFTKLYQIPQTDMAECAEKLFDLVDGFAESTKRKAAVWPLQII } \\ \text { Equus caballus } & \text { AVINSLEKAFWNWVENYPDEFTKLYQIPQTDMAECAEKLFDLVDGFAESTKRKAAVWPLQII } \\ \text { Ailuropoda melanoleuca } & \text { AVINSLEKAFWNWVENYPDEFTKLYQIPQTDMAECAEKLFDLVDGFAESTKRKAAVWPLQII } \\ \text { Macaca mulatta } & \text { AVINSLEKAFWNWVENYPDEFTKLYQIPQTDMAECAEKLFDLVDGFAESTKRKAAVWPLQII } \\ \text { Oryctolagus cuniculus } & \text { AVINSLEKAFWNWVENYPDEFTKLYQIPQTDMAECAEKLFDLVDGFAESTKRKAAVWPLQII } \\ \begin{array}{l}\text { Mus musculus } \\ \text { Drosophila melanogaster }\end{array} & \text { AVINSLEKAFWNWVENYPDEFTKLYQIPQTDMAECAEKLFDLVDGFAESTKRKAAVWPLQII } \\ & \text { AVINSEKAFWNWVENYPDEFTKLYQIPQTDMAECAGKLFDLVDGFAESTKRKAAVWPLQII }\end{array}$

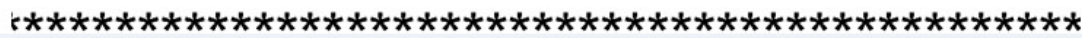

Figure 4. Mutation involving a highly conserved region. The frameshift mutation disrupt amino acid sequence starts at position 234; this region is highly conserved for NF1, which is demonstrated by analysis of orthologs from eight different species. 


\section{DISCUSSION}

Neurofibromatosis type 1 is the most common autosomal dominant disorder with equal gender incidence (Huson et al., 1989). The presentation of most disease manifestations is agedependent and its penetrance is thought to approach 100\% by age 20 (Boyd et al., 2009). Significant advances in the understanding of NF1 stemmed from the discovery of the NF1 gene (Cawthon et al., 1990; Viskochil et al., 1990; Wallace et al., 1990). Neurofibromin, the NF1 gene protein product, has an RAS-GTPase activating protein-related domain that can inactive p21-RAS by activating the intrinsic GTPase of p21-RAS-GTP to hydrolyze GTP to GDP (Xu et al., 1990; Golubic et al., 1992). RAS is a key component of many growth factor signaling pathways, indicating that neurofibromin serves as a regulator of signals for cell proliferation and differentiation, and in the absence of neurofibromin, it will drive uncontrolled cell proliferation (Viskochil, 1999). Therefore, $N F 1$ is thought to act as a tumor suppressor gene. To date, many types of mutations have been identified, such as chromosome abnormalities, insertions, deletions, point mutations, 3 '-untranslated region mutations, stop mutations, and splicing mutations (Boyd et al., 2009; Rasmussen and Friedman, 2000). However, no true "hotspots" have been found in NF1. In this Chinese pedigree, a frame-shift mutation (c.702_703delGT) in exon 7 was identified in all affected patients, but not in any normal family member or healthy control. This c.702_703delGT NF1 mutation produced a premature stop codon at position 720, which resulted in a truncated protein of 240 -amino acid residues instead of full-length neurofibromin. The frame-shift mutation occurred at the first half of the gene in a region that is highly conserved for NF1 based on analysis of orthologs from 8 different species, including Homo sapiens, Pan paniscus, Equus caballus, Ailuropoda melanoleuca, Macaca mulatta, Oryctolagus cuniculus, Mus musculus, and Drosophila melanogaster (Figure 4). Such a high degree of conservation argues for a functional importance of the relevant amino acid sequence. However, the NF1 protein may not exist at all in these affected patients based on nonsense-mediated mRNA decay (Muhlrad and Parker, 1994; Hentze and Kulozik, 1999; Wagner and Lykke-Andersen, 2002). Nonsense-mediated mRNA decay is a surveillance mechanism by which cells recognize and degrade mRNAs containing premature translation termination codons. Therefore, this genetic variant appears to be the causative mutation for the disease in this family.

To date, no obvious corresponding relationships between particular NF1 mutations and resulting clinical manifestations have been identified. Our study also showed this absence of a close genotype-phenotype relationship, as patients in this pedigree presented different sizes of subcutaneous neurofibromas and other clinical manifestations. This feature suggests that other factors, including modifying genes, environmental influences, and stochastic factors, are likely involved in determining clinical manifestations (Rasmussen and Friedman, 2000).

In conclusion, the c.702_703delGT mutation in NF1 in this pedigree appears to be the cause of NF1 in this family. This is the first time that this frame-shift mutation was found and this study adds a novel mutation to the existing spectrum of NF1 mutations in patients with NF1 and provides further evidence that the loss or diminished function of the neurofibromin leads to neurofibromatosis type 1 .

\section{Conflicts of interest}

The authors declare no conflict of interest. 


\section{ACKNOWLEDGMENTS}

The authors are deeply grateful to all of the family members for their cooperation in this study. Research supported by grants from the National Natural Science Foundation of China (NNSF \#81270995, \#81170851, and \#81371009).

\section{REFERENCES}

Anonymous (1988). Neurofibromatosis. Conference statement. National Institutes of Health Consensus Development Conference. Arch. Neurol. 45: 575-578.

Bausch B, Borozdin W, Mautner VF, Hoffmann MM, et al. (2007). Germline NF1 mutational spectra and loss-ofheterozygosity analyses in patients with pheochromocytoma and neurofibromatosis type 1. J. Clin. Endocrinol. Metab. 92: 2784-2792.

Bottillo I, Ahlquist T, Brekke H, Danielsen SA, et al. (2009). Germline and somatic NF1 mutations in sporadic and NF1associated malignant peripheral nerve sheath tumours. J. Pathol. 217: 693-701.

Boyd KP, Korf BR and Theos A (2009). Neurofibromatosis type 1. J. Am. Acad. Dermatol. 61: 1-14.

Cai Y, Fan Z, Liu Q, Li J, et al. (2005). Two novel mutations of the NF1 gene in Chinese Han families with type 1 neurofibromatosis. J. Dermatol. Sci. 39: 125-127.

Cawthon RM, Weiss R, Xu GF, Viskochil D, et al. (1990). A major segment of the neurofibromatosis type 1 gene: cDNA sequence, genomic structure, and point mutations. Cell 62: 193-201.

Clementi M, Barbujani G, Turolla L and Tenconi R (1990). Neurofibromatosis-1: a maximum likelihood estimation of mutation rate. Hum. Genet. 84: 116-118.

Golubic M, Roudebush M, Dobrowolski S, Wolfman A, et al. (1992). Catalytic properties, tissue and intracellular distribution of neurofibromin. Oncogene 7: 2151-2159.

Gutmann DH, Aylsworth A, Carey JC, Korf B, et al. (1997). The diagnostic evaluation and multidisciplinary management of neurofibromatosis 1 and neurofibromatosis 2. JAMA 278: 51-57.

Heim RA, Kam-Morgan LN, Binnie CG, Corns DD, et al. (1995). Distribution of 13 truncating mutations in the neurofibromatosis 1 gene. Hum. Mol. Genet. 4: 975-981.

Hentze MW and Kulozik AE (1999). A perfect message: RNA surveillance and nonsense-mediated decay. Cell 96: 307-310.

Huson SM and Hughes RAC (1994). The Neurofibromatoses: A Pathogenetic and Clinical Overview. Chapman and Hall Medical, London, 487.

Huson SM, Compston DA, Clark P and Harper PS (1989). A genetic study of von Recklinghausen neurofibromatosis in south east Wales. I. Prevalence, fitness, mutation rate, and effect of parental transmission on severity. J. Med. Genet. 26: 704-711.

Li Y, O'Connell P, Breidenbach HH, Cawthon R, et al. (1995). Genomic organization of the neurofibromatosis 1 gene (NF1). Genomics 25: 9-18.

Littler M and Morton NE (1990). Segregation analysis of peripheral neurofibromatosis (NF1). J. Med. Genet. 27: 307-310.

Messiaen L, Vogt J, Bengesser K, Fu C, et al. (2011). Mosaic type-1 NF1 microdeletions as a cause of both generalized and segmental neurofibromatosis type-1 (NF1). Hum. Mutat. 32: 213-219.

Muhlrad D and Parker R (1994). Premature translational termination triggers mRNA decapping. Nature 370: 578-581.

North K (1993). Neurofibromatosis type 1: review of the first 200 patients in an Australian clinic. J. Child Neurol. 8: 395-402.

Origone P, De Luca A, Bellini C, Buccino A, et al. (2002). Ten novel mutations in the human neurofibromatosis type 1 (NF1) gene in Italian patients. Hum. Mutat. 20: 74-75.

Rasmussen SA and Friedman JM (2000). NF1 gene and neurofibromatosis 1. Am. J. Epidemiol. 151: 33-40.

Riccardi VM (1992). Neurofibromatosis: Phenotype, Natural History, and Pathogenesis. 2nd edn. The Johns Hopkins University Press, Baltimore.

Szudek J, Birch P, Riccardi VM, Evans DG, et al. (2000). Associations of clinical features in neurofibromatosis 1 (NF1). Genet. Epidemiol. 19: 429-439.

Takano T, Kawashima T, Yamanouchi Y, Kitayama K, et al. (1992). Genetics of neurofibromatosis 1 in Japan: mutation rate and paternal age effect. Hum. Genet. 89: 281-286.

Upadhyaya M, Osborn MJ, Maynard J, Kim MR, et al. (1997). Mutational and functional analysis of the neurofibromatosis type 1 (NF1) gene. Hum. Genet. 99: 88-92.

Upadhyaya M, Kluwe L, Spurlock G, Monem B, et al. (2008). Germline and somatic NF1 gene mutation spectrum in NF1- 
associated malignant peripheral nerve sheath tumors (MPNSTs). Hum. Mutat. 29: 74-82.

Viskochil D (1999). The Structure and Function of the NF1 Gene: Molecular Pathophysiology (Friedman JM, Gutmann DH, MacCollin M and Riccardi VM, eds.). In: Neurofibromatosis: Phenotype, Natural History, and Pathogenesis. Johns Hopkins University Press, Baltimore, 19-141.

Viskochil D, Buchberg AM, Xu G, Cawthon RM, et al. (1990). Deletions and a translocation interrupt a cloned gene at the neurofibromatosis type 1 locus. Cell 62: 187-192.

Von Deimling A, Foster R and Krone W (2000). Familial Tumor Syndromes Involving the Nervous System (Kleihues P and Cavenee WK, eds.). In: Pathology and Genetics Tumours of the Nervous System. IARC Press, Lyon, 216-218.

Wagner E and Lykke-Andersen J (2002). mRNA surveillance: the perfect persist. J. Cell Sci. 115: 3033-3038.

Wallace MR, Marchuk DA, Andersen LB, Letcher R, et al. (1990). Type 1 neurofibromatosis gene: identification of a large transcript disrupted in three NF1 patients. Science 249: 181-186.

Xu GF, Lin B, Tanaka K, Dunn D, et al. (1990). The catalytic domain of the neurofibromatosis type 1 gene product stimulates ras GTPase and complements ira mutants of $S$. cerevisiae. Cell 63: 835-841. 